whereas active enthesitis was associated with higher PASI $(5.4 \pm 3.0$ vs $3.7 \pm 2.9$, $\mathrm{p}=0.02$ ). No significant differences were found between Pso patients and HCs for the structural damage (i.e. osteoproliferation and erosions), both for joints and enthesis.

Abstract SAT0304 - Table 1. * p significant Pso with CA vs HCs; ** p significant Pso with CA vs Pso without CA

\begin{tabular}{|c|c|c|c|}
\hline Baseline data & $\begin{array}{c}\text { Pso without CA } \\
(n=41)\end{array}$ & Pso with CA (n= 23) & Healthy controls $(n=21)$ \\
\hline Age mean $( \pm \mathrm{SD})$ & $51.37( \pm 15.88)$ & $49.91( \pm 14.23)$ & $45.76( \pm 15.89)$ \\
\hline Female n. (\%) & $23(56.1 \%)$ & $10(43.5 \%)$ & $12(57.1 \%)$ \\
\hline Smoking n. (\%) & $12(29.3 \%)$ & $2(9.0 \%)$ & $6(38.6 \%)$ \\
\hline$B M I$ mean $( \pm S D)$ & $25(4.0 \%)$ & $27( \pm 4.3 \%)$ & $24( \pm 4.2)$ \\
\hline Clinimetric data & $\begin{array}{c}\text { Pso without CA } \\
\quad(n=41)\end{array}$ & Pso with CA (n= 23) & Healthy controls $(n=21)$ \\
\hline VAS pain $(0-10)$ mean ( $(\mathrm{SD})$ & $2( \pm 2.4)$ & $4( \pm 2.4)^{* * *}$ & $2( \pm 2.35)$ \\
\hline $\mathrm{HAQ}$ mean ( $\pm \mathrm{SD})$ & $0( \pm 0.31)$ & $0( \pm 0.45) * * *$ & $0( \pm 0.21)$ \\
\hline Joints tenderness mean & 0.34 per patient & 2.56 per patient $* * *$ & 0.17 per patient \\
\hline Comorbidities & $\begin{array}{c}\text { Pso without CA } \\
\quad(n=41)\end{array}$ & Pso with CA (n= 23) & Healthy controls $(n=21)$ \\
\hline Obesity n. (\%) & $4(9.8 \%)$ & $0(0 \%)$ & $1(4.8 \%)$ \\
\hline Diabetes Mellitus n. $(\%)$ & $3(7.3 \%)$ & $0(0 \%)$ & $2(9.5 \%)$ \\
\hline Hypertension n. (\%) & $7(17.0 \%)$ & $7(30.4 \%)$ & $5(23.8 \%)$ \\
\hline Metabolic syndrome $\mathrm{n} .(\%)$ & $5(12.2 \%)$ & $3(13.4 \%)$ & $4(19.0 \%)$ \\
\hline Fatty liver disease $\mathrm{n} .(\%)$ & $5(12.2 \%)$ & $4(17.4 \%)$ & $1(4.8 \%)$ \\
\hline Uveitis $\mathrm{n} .(\%)$ & $2(4.9 \%)$ & $0(0 \%)$ & $0(0 \%)$ \\
\hline Depression n. (\%) & $2(4.9 \%)$ & $3(13.0 \%)$ & $0(0 \%)$ \\
\hline CV disease n.(\%) & $3(7.3 \%)$ & $0(0 \%)$ & $1(4.8 \%)$ \\
\hline
\end{tabular}

Conclusions: In Psoriasis subclinical US active synovitis and/or enthesitis are present in $20 \%-30 \%$ of patients. In Pso the comparison between groups, with or without CA, show no significant difference in active subclinical synovitis or enthesitis, but Pso patients with CA present more frequently US tenosynovitis or paratenonitis. In Pso subclinical US synovitis or enthesitis are significantly associated with higher NAPSI and PASI. The relevance of these results, to possibly identify a subgroup of Pso more prone to develop PsA, deserve further investigation and prospective evaluation.

Disclosure of Interest: None declared

DOI: 10.1136/annrheumdis-2018-eular.4305

\section{SAT0305 1 ASSESSMENT OF SUB CLINICAL HAND JOINT SYNOVITIS IN PATIENTS WITH PSORIATIC ARTHRITIS AND PSORIASIS BY ULTRASOUND AND ITS RELATIONSHIP WITH CLINICAL DISEASE ACTIVITY}

S. Mondal ${ }^{1}$, R.P. Goswami ${ }^{1}$, D. Sinha ${ }^{1}$, G.B. Sircar ${ }^{1}$, A.K. Das ${ }^{2}$, P. Ghosh ${ }^{1}$, A. Ghosh ${ }^{1} .{ }^{1}$ Rheumatology, IPGMER; ${ }^{2}$ Orthopaedics, West Bengal Health Service, Kolkata, India

Background: Articular involvement in Psoriatic arthritis (PsA) can have diverse presentations; oligoarticular involvement is predominant in early disease. Ultrasound (US) detected subclinical synovitis can be present in early PsA and a substantial portion of oligoarthritic PSA patients are being reclassified as having polyarthritis. ${ }^{1}$ Asymptomatic US synovitis and enthesopathy can be present in Psoriasis (Pso) patients which probably indicate subclinical musculoskeletal involvement. $^{2}$

Objectives:

- To evaluate sub-clinical synovitis of hand joints in patients with PsA and Pso by B-mode and Power Doppler US.

- Correlation of PsA and Pso disease activity with US detected synovitis.

Methods: 27 patients of PsA (disease duration $<2$ years, no clinical evidence of hand joint involvement), 36 Pso patients and 30 controls were recruited. PASI and DAPSA score used for assessment of cutaneous and articular disease activity respectively. US [grey scale (GS) and power Doppler (PD)] used to assess synovitis of hand joints. A GS score $\geq 2$ and/or a PD score $\geq 1$ were used to identify US detected synovitis.

Results: Significantly more patients with PsA had sub-clinical hand joint synovitis than controls $(62.96 \%$ versus $20 \%$, $p$ value $=0.001$, relative risk: $3.148,95 \%$ C.I: 1.455 to 6.814$)$, and Pso patients [(27.78\%), p value $=0.0095$, relative risk $=2.267$, $95 \%$ C.I: 1.243 to 4.135$]$. Median number of joints involved in PsA group was 4 (inter quartile range: $2-5$ ). Among 810 hand joints scanned in PsA group, 59 $(7.28 \%)$ joints showed evidence of sub-clinical synovitis. Wrist joint was most commonly involved $(28.81 \%)$, followed by DIP3 (13.56\%) and MCP3 $(10.17 \%)$ Less involvement noted in MCP4, MCP5, PIP1, PIP5 and DIP5 (1.69\%). In Pso patients, evidence of sub-clinical synovitis was not significantly different from control. ( $p$ value $=0.5689$, relative risk $=1.389,95 \%$ C.I: 0.5710 to 3.378 ). However, wrist and DIP involvement was significantly more in Pso than control. No correlation noted between numbers of joints with subclinical synovitis with DAPSA or PASI score.

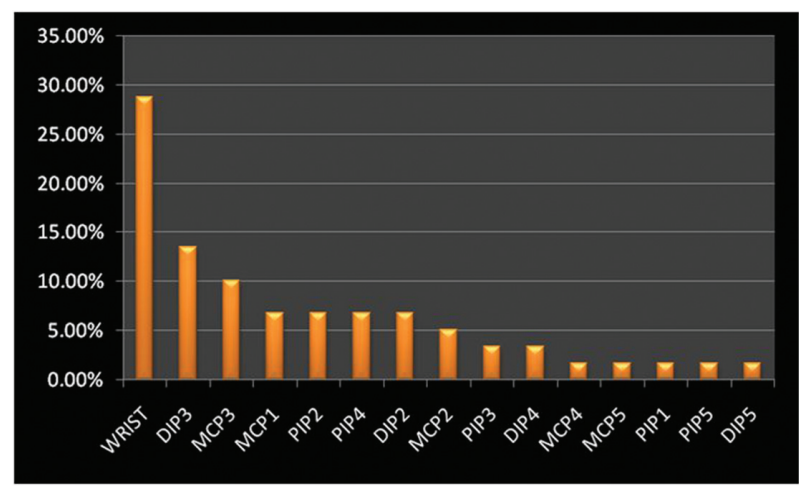

Conclusions:

- Almost two third patients with early PsA had PDUS evidence of subclinical synovitis in hand joints, most commonly in wrist joint followed by DIP3 and MCP3.

- No significant increase of sub-clinical synovitis in Pso compared to control group. However, wrist and DIP joint involvement was significantly more in Psoriasis.

- There was no correlation between number of joints with sub-clinical synovitis and disease activity indices.

\section{REFERENCES:}

[1] Freeston JE, Coates LC, Nam JL, et al. Is there subclinical synovitis in early psoriatic arthritis? A clinical comparison with gray-scale and power Doppler ultrasound. Arthritis Care Res (Hoboken) 2014 Mar;66(3):432-9.

[2] Naredo E, Möller I, de Miguel E, et al. High prevalence of ultrasonographic synovitis and enthesopathy in patients with psoriasis without psoriatic arthritis: a prospective case-control study. Rheumatology (Oxford) 2011;50 (10):1838-48.

Disclosure of Interest: None declared

DOI: 10.1136/annrheumdis-2018-eular.1977

\section{SAT0306 FINGER FLEXOR TENDON PULLEY COMPLEX INVOLVEMENT IN PSA DACTYLITIS: AN ULTRASONOGRAPHY STUDY}

I. Tinazzi ${ }^{1}$, D. Mc Gonagle ${ }^{2}$, A. Zabotti ${ }^{3}$, P. Macchioni ${ }^{4}$, S.Z. Aydin ${ }^{5}$

${ }^{1}$ Rheumatology, Ospedale Sacro Cuore Negrar (Verona), Negrar Verona, Italy; ${ }^{2} 2$ NIHR Leeds Musculoskeletal Biomedical Research Unit, Leeds, UK; ${ }^{3}$ AOU "Santa Maria della Misericordia", Udine; ${ }^{4}$ Rheumatology, Ospedale S.Maria Nuova, Reggio Emilia, Italy; ${ }^{5}$ The Ottawa Hospital Research Institute, Ottawa, Canada

Background: Dactylitis is a hallmark of psoriatic arthritis (PsA) occurring in around $40 \%$ of cases at some point in the disease course. At the micro anatomical level PsA is strongly linked to disease localisation to entheses and other sites of high mechanical stress. Recently high resolution MRI has shown prominent abnormalities at the mini-entheses of the flexor tendon pulleys may be common Objectives: . In this study we aimed to understand the changes within the pulleys for patients with PsA, with or without dactylitis to explore the role of the pulley disease in the dactylitis.

Methods: Consecutive 20 cases of PsA with dactylitis were recruited and had an US scan of the A1, A2 and A4 pulleys of the digit with dactylitis and the contralateral side. A high resolution probe (22 MHZ) was used to explore a) the thickness of the pulleys, $b$ ) the presence of Doppler signals. A comparison was made within digits with or without dactylitis

\begin{tabular}{lccc}
\hline & $\begin{array}{c}\text { Dactylitis }(- \\
\text { ( }\end{array}$ & $\begin{array}{c}\text { Dactylitis } \\
(+)\end{array}$ & $p$ \\
\hline $\begin{array}{l}\text { A1- } \\
\text { longitudinal }\end{array}$ & $0.69(0.10)$ & $1.00(0.34)$ & 0.001 \\
$\begin{array}{l}\text { A2- } \\
\text { longitudinal }\end{array}$ & $0.77(1.11)$ & $0.75(0.15)$ & $<0.001$ \\
$\begin{array}{l}\text { A4- } \\
\text { longitudinal }\end{array}$ & $0.50(.089)$ & $0.65(0.15)$ & $<0.001$ \\
A1- transverse & & & $<0.001$ \\
A2- transverse & $0.68(0.10)$ & $1.01(0.33)$ & $<0.001$ \\
A4- transverse & $0.51(0.09)$ & $0.73(0.16)$ & $<0.001$ \\
\hline
\end{tabular}

